\title{
METHODS OF ANALYZING QUALITATIVE VARIABLE CORRELATION ON THE REAL ESTATE MARKET ${ }^{1}$
}

\author{
Krzysztof Dmytrów \\ Institute of Econometrics and Statistics \\ University of Szczecin \\ e-mail: kszysztof.dmytrow@usz.edu.pl, ORCID: https://orcid.org/0000-0001-7657-6063 \\ Anna Gdakowicz \\ Institute of Econometrics and Statistics \\ University of Szczecin \\ e-mail: anna.gdakowicz@usz.edu.pl, ORCID: https://orcid.org/0000-0002-4360-3755
}

\author{
Ewa Putek-Szeląg \\ Institute of Econometrics and Statistics \\ University of Szczecin \\ e-mail:ewa.putek-szelag@usz.edu.pl
}

\begin{abstract}
Variables occurring in a real estate market are frequently presented on scales other than interval or ratio scales. Most frequently, the scale is an ordinal (for instance - onerous, unfavourable, neutral, favourable), or possibly a nominal one. That is why the use of scales intended for quantitative attributes (such as Pearson linear correlation coefficient) is not possible. The paper presents the results of employing other coefficients (Kendall's $\tau_{B}$ and Spearman's $\rho$ coefficients) in analyzing correlations on the real estate market.

The objective of the article is to present a method of analyzing the correlation of qualitative variables (attributes) and to present the possibility of using the obtained results in the process of real estate appraisal.
\end{abstract}

Key words: qualitative variables, Kendall's $\tau_{B}$ correlation coefficient, Spearman's $\rho$ coefficient, real estate attributes.

JEL Classification: C10, R33.

Citation: Dmytrów, K., Gdakowicz, A. \& Putek-Szeląg, E. (2020). Methods of analysing qualitative variables correlation on the real estate market. Real Estate Management and Valuation, 28(1), 80-90.

DOI: https:// doi.org/10.2478/remav-2020-0007

\section{Introduction}

Real estate market analyses are conducted for a variety of purposes. They aim to provide information concerning the value of real estate, the most likely price or price changes. Real estate is described in terms of a number of attributes - the wider the range of properties used, the more precise the achieved results can be. Real estate attributes are not only quantitative properties (presented on an interval or

1 The article is financed within the framework of the National Science Centre project, registration No. 2017/25/B/HS4/01813. 
ratio scale), but increasingly often qualitative ones (presented on a nominal or ordinal scale) are also used. The choice of qualitative and quantitative variables describing a real property enables a more complete understanding of the problems and motivations occurring on the market (Bell \& Bell, 2015).

The set of real estate attributes affects the possibility of employing measures and algorithms describing the existing relationships. The problem takes on a special meaning in the case of estimating the value of real estate. The methods used in defining real estate value assume that the conducted calculations should account for real estate that is the most similar to the appraised real property. Such similarity is defined on the grounds of a set of attributes of the greatest significance in terms of their impact on real estate value. Previously, attributes were selected on the basis of the appraiser's research experience. The use of statistical methods in the process of real estate valuation requires the employment of procedures that ensure objectivity and repeatability of the conducted computations, and needs to account for the specificity of the available data. The article presents selected coefficients for analysing the interdependence of qualitative properties with real estate may be described by. The impact of individual attributes on the value of $1 \mathrm{~m}^{2}$ of land real estate was analysed. An empirical study was conducted on the grounds of an appraisers' data base comprising land real estate in Szczecin designated for residential purposes. The real estate was valued over the course of 2005-2007. The defined correlation measures may be used for determining the weights of individual attributes in the process of valuation, also including mass appraisal.

\section{Methodology of the analysis of real estate qualitative attributes}

The effectiveness of the application of qualitative methods in analyses concerning the real estate market is linked, inter alia, to the proper classification of variables and the use of suitable measures that take into account their character. It is important for a researcher to be able to precisely define what measurement scale they can present the gathered data on, as various scales require the employment of different numerical procedures (Steczkowski \& Zeliaś, 1997). Currently the division of scales proposed by S.S. Stevens (1946) is commonly used. He distinguished a nominal, ordinal, interval and ratio scales - from the weakest to the strongest one.

Real estate attributes may be presented on different types of scales. Frequently those are qualitative attributes described on "weak" scales - a nominal and an ordinal one (e.g. neighbourhood favourable, unfavourable; real estate purpose - residential, commercial, etc.). The set of real estate characteristics additionally includes quantitative attributes presented on a ratio scale (e.g. area, cubic capacity, distance from the centre). If we want to analyse the attributes of a real estate property by means of statistical or econometric methods, all of them must be presented on the same scale. In order to consider all variables for the analyses, all of them must be transformed into the weakest measurement scale (Walesiak, 1996; Foryś \& Gaca, 2016).

An increasingly more common use of statistical and econometric methods in the process of real estate appraisal (particularly mass appraisal) necessitates the use of methods adequate to the quality of attributes that researchers have at their disposal. The use of correlation coefficients for qualitative variables on the real estate market was proposed by, inter alia, (Barańska, 2009; Kulczycki \& Ligas 2014; Butryn \& Preweda, 2017; Doszyń, 2017; Gaca, 2018).

\section{Methods of analysing the correlation of qualitative variables}

Real estate attributes found on the real estate market, such as area, utilities, neighbourhood, location and others, are typically presented on an ordinal scale, even though many of them (e.g. area) can be measured on a strong scale (ratio scale). That is why, when analysing the correlations occurring on that market, the most commonly used Pearson product-moment correlation coefficient cannot be employed, because its application requires both variables to be measured on at least an interval scale. The coefficients that can be used instead are those enabling the study of correlations if the attributes are measured on nominal or ordinal scales. The coefficients based on $\chi^{2}$ statistics (T Tschuprow's $T$ coefficient, Cramer's $V$ coefficient, or Pearson's $\varphi$ coefficient) belong to one group, intended for analysing the strength of a relationship between the attributes measured on a nominal scale. The second group is made up of the coefficients based on ranks, intended for the attributes measured on at least an ordinal scale. These are: Spearman's $\rho$ rank correlation coefficient (Babatunde, 2018, p. 98), Kendall's $\tau$ coefficient (Kendall, 1955) and general correlation coefficient $\Gamma$.

In the present paper, Kendall's $\tau_{B}$ and Spearman's $\rho$ rank correlation coefficients are used and both of them involve tied ranks. The assumptions made for calculating Kendall's $\tau_{B}$ coefficient are as 
follows:

- The data are presented with a correlation series.

- Observations are joined in all possible pairs: $\left(x_{j}, y_{j}\right)$ and $\left(x_{k}, y_{k}\right), j \neq k$.

- If both $x_{j}>x_{k}$ and $y_{j}>y_{k}$ or $x_{j}<x_{k}$ and $y_{j}<y_{k}$, then such a pair is called concordant. The number of such pairs is marked by $n_{c}$.

- If both $x_{j}>x_{k}$ and $y_{j}<y_{k}$ or $x_{j}<x_{k}$ and $y_{j}>y_{k}$, then such a pair is called discordant. The number of such pairs is marked by $n_{d}$.

- If $x_{j}=x_{k}$ or $y_{j}=y_{k}$, then such a pair is neither concordant nor discordant. It is a tied pair.

Kendall's $\tau_{B}$ coefficient is calculated as follows:

$$
\tau_{B}=\frac{n_{c}-n_{d}}{\sqrt{\left(n_{0}-n_{1}\right)\left(n_{0}-n_{2}\right)}},
$$

where:

$$
\begin{gathered}
n_{0}=\frac{n(n-1)}{2}, \\
n_{1}=\frac{\sum_{j} t_{j}\left(t_{j}-1\right)}{2}, \\
n_{2}=\frac{\sum_{k} u_{k}\left(u_{k}-1\right)}{2},
\end{gathered}
$$

$t_{j}$ - the number of observations in a sample having the same $j$-th rank value of $x$ attribute,

$u_{k}$ - the number of observations in a sample having the same $k$-th rank value of $y$ attribute.

Kendall's $\tau_{B}$ correlation coefficient is symmetrical; it is contained within $\langle-1 ; 1\rangle$ range - measures both the strength as well as the direction of a relation.

Spearman's $\rho$ rank correlation coefficient is measured as follows (KENDALL 1948, p. 29):

$$
\rho_{x y}=\rho_{y x}=\frac{\frac{1}{6}\left(n^{3}-n\right)-\sum_{i=1}^{n} d_{i}^{2}-T_{x}-T_{y}}{\sqrt{\left(\frac{1}{6}\left(n^{3}-n\right)-2 T_{X}\right)\left(\frac{1}{6}\left(n^{3}-n\right)-2 T_{Y}\right)}}
$$

where:

$$
\begin{gathered}
d_{i}=\operatorname{rank} x_{i}-\operatorname{rank} y_{i}, \\
T_{x}=\frac{1}{12} \sum_{j}\left(t_{j}^{3}-t_{j}\right), \\
T_{y}=\frac{1}{12} \sum_{k}\left(u_{k}^{3}-u_{k}\right),
\end{gathered}
$$

$t_{j}$ - the number of observations in a sample having the same $j$-th rank value of $x$ attribute,

$u_{k}$ - the number of observations in a sample having the same $k$-th rank value of $y$ attribute,

$n$ - the number of observations.

Spearman's $\rho$ rank correlation coefficient is also symmetrical and contained within the $\langle-1 ; 1\rangle$ range - it measures both the strength as well as the direction of a relation.

When analysing the impact of the attributes affecting the value of $1 \mathrm{~m}^{2}$ of a real property, it can be noted that frequently the analysed properties are tied to one another (the phenomenon of collinearity occurs). That is why an analysis of their impact on the value of $1 \mathrm{~m}^{2}$ ought to be conducted without taking into account the influence of the remaining characteristics (attributes). It can be analysed with the help of a partial correlation coefficient. To that end, a matrix of correlation coefficients between all variables needs to be calculated, denoted by $R$.

Correlation matrices are created on the basis of the measure of: Kendall's $\tau_{B}$ and Spearman's $\rho_{x y}$. Kendall's $\tau_{B}$ partial correlation coefficient is computed as follows:

where:

$$
\tau_{y x . z}=-\frac{R_{12}}{\sqrt{R_{11} \cdot R_{22}}}
$$

$\tau_{y x . z}$ - Kendall $\tau_{B}$ partial correlation coefficient,

2 Partial correlation coefficient for Spearman's $\rho$ coefficient is computed similarly in accordance with the same formula. 
$y$ - vector of explained variable,

$x$ - vector of explaining variable,

$z \quad$ - vector (or matrix) of the remaining variables,

$R_{12}$ - determinant of cofactor matrix created by the removal of a row corresponding to $y$ variable and column corresponding to the $x$ variable.

$R_{11}$ - determinant of cofactor matrix created by the removal of a row and column corresponding to the $y$ variable

$R_{22}$ - determinant of cofactor matrix created by the removal of a row and column corresponding to the $x$ variable.

\section{Verification of calculated correlation coefficients}

In order to verify the usefulness of the estimated correlation coefficients in the process of real estate appraisal, the data base of land real estate value was divided into two parts. The first part, constituting a randomly selected group of approximately $10 \%$ of all real estates constituted the basis on which the consistence of the obtained results was verified. The second part - the remaining real properties - served as the basis on the grounds of which $W W R_{j}$ market value ratios were determined.

The details of the procedure were as follows. In the first step, partial correlation coefficients (Kendall or Spearman) between each attribute and the value of $1 \mathrm{~m}^{2}$ of appraised real estates were calculated by means of Formula (3). Based on the computed correlation coefficients, the impact of individual attributes on real estate value was appraised. To that aim, the obtained partial correlation coefficients were corrected so that the sum of the significant coefficients was equal to 1 and each coefficient created the weight of each attribute, significantly influencing the value of $1 \mathrm{~m}^{2}$ of appraised real estates. Such a method of calculating weights is based on the approach proposed by Kolenda (2006). The above-mentioned procedure is based on the assumption that all partial correlation coefficients are non-negative. If this assumption is not satisfied, this means that the quality of the database is poor - in such a case, the attribute for which the partial correlation coefficient is negative should be removed and all coefficients should be re-calculated.

Following that, land real estate attributes were calibrated. During that process the following mathematical formula was used. Correction coefficients $\left(1+A_{k p}\right)$ were determined according to a distance method on extreme values (LIS 2008):

$$
1+A_{k p}=\left(1-\frac{1}{2} \hat{\beta}_{k}\right)+\left[\left(1+\frac{1}{2} \hat{\beta}_{k}\right)-\left(1-\frac{1}{2} \hat{\beta}_{k}\right)\right] \cdot \frac{l_{k p}}{k_{p}-1}=\left(1-\frac{1}{2} \hat{\beta}_{k}\right)+\hat{\beta}_{k} \frac{l_{k p}}{k_{p}-1}
$$

where:

$A_{k p} \quad$ - the impact of $p$-th state of $k$-th attribute $\left(k=1,2, \ldots, K ; p=1,2, \ldots, k_{p}\right)$

$\hat{\beta}_{k} \quad$ - corrected Spearman's $\rho$ rank correlation coefficient or corrected Kendall's $\tau_{B}$ coefficient,

$l_{k p} \quad-$ value of $k$-th attribute,

$k_{p} \quad-$ number of categories of $k$-th attribute,

$K \quad$ - number of attributes.

The above calculations enabled assessing the impact that individual attribute states have on a real estate value.

The next step involved appraising real estate hypothetical value $\left(\widehat{W}_{h i}\right)$ for the basic data base, and then transforming the value of $W W R_{j}$ in the following steps:

where:

$$
\begin{gathered}
\widehat{W}_{h i}=\operatorname{pow}_{i} \cdot W_{b a z} \cdot \prod_{p=1}^{k_{p}} \prod_{k=1}^{K}\left(1+A_{k p i}\right) \\
W W R_{i}=\frac{W R_{r i}}{\widehat{W}_{h i}} \\
W W R_{j}=\frac{\sum_{i=1}^{l} W W R_{i}}{l}
\end{gathered}
$$

$\widehat{W}_{h i} \quad$ - hypothetical real estate value calculated on the grounds of the model,

$W_{b a z} \quad$ - value of $1 \mathrm{~m}^{2}$ of the cheapest land in the appraised area,

$W W R_{i}$ - ratio of market value to hypothetical value of $i$-th real estate,

$W R_{r i} \quad$ - market value of $i$-th real estate defined by a property appraiser,

$W W R_{j}$ - market value ratio in $j$-th location attractiveness zone $(j=1,2, \ldots, J)$,

$A_{k p i} \quad$ - the impact of $p$-th state of $k$-th attribute $\left(k=1,2, \ldots, K ; p=1,2, \ldots, k_{p}\right)$ in $i$-th real estate, 
$J \quad$ - number of location attractiveness zones,

pow $_{i} \quad$ - area of $i$-th real estate,

$l \quad-$ number of real properties in $j$-th location attractiveness zone.

$W W R_{j}$ estimated for individual location attractiveness zones were used to appraise the values of 56 previously randomly selected real properties. The values of real properties found in the data base were obtained through the application of the following formula:

where:

$$
\widehat{W}_{j i}=W W R_{j} \cdot \operatorname{pow}_{i} \cdot W_{b a z} \cdot \prod_{p=1}^{k_{p}} \prod_{k=1}^{K}\left(1+A_{k p i}\right),
$$

$\widehat{W}_{j i} \quad$ - market (or cadastral) value of $i$-th real estate in $j$-th location attractiveness zone, the remaining designations remain the same as in the formulas presented above (4-7).

For 56 selected real properties (test dataset) the obtained values were confronted with the real estate values obtained by way of individual appraisal. The comparison of the consistency of obtained results was carried out with the use of a relative appraisal error, residual deviation and a coefficient of variation. Relative forecast error was computed by means of the MAPE (Mean Absolute Percentage Error):

where:

$$
\text { MAPE }=\frac{1}{n} \sum_{i=1}^{n} \frac{\left|\widehat{W}_{j i}-W R_{r i}\right|}{\widehat{W}_{j i}} \cdot 100 \%
$$

$n$ - number of real estates.

\section{Empirical data}

The study was conducted using data concerning 567 land plots in Szczecin designated for residential purposes, which were subject to individual appraisal in 2005. The real properties were located in 5 location attractiveness zones. Before commencing the calculation of the coefficients, 56 real properties were removed from the data bases, which were then appraised with the application of the Szczecin Algorithm of Real Estate Mass Appraisal (SAREMA).

The plots were described with the following attributes:

$y$ - value of $1 \mathrm{~m}^{2}$ (in PLN) - explained variable;

$x_{1}$ - physical properties: 0 - unfavourable, 1 - average, 2 - favourable;

$x_{2}$ - building development: 0 - no, 1 - yes;

$x_{3}$ - utilities: 0 - none, 1 - partial, 2 - complete;

$x_{4}$ - neighbourhood: 0 - onerous, 1 - unfavourable, 2 - average, 3 - favourable;

$x_{5}$ - road access: 0 - unfavourable, 1 - average, 2 - favourable;

$x_{6}$ - location: 0 - unfavourable, 1 - average, 2 - favourable;

$x_{7}$ - area: 0 - large, 1 - average, 2 - small;

$x_{8}$ - soil-water conditions: 0 -poor, 1 - unfavourable, 2 - average, 3 - favourable.

The attribute of "physical properties" was determined on the basis of plot shape. It was assumed that a rectangle with a side length ratio of 3:2 was an optimum plot shape. Having the data concerning a plot circumference, its area was calculated, assuming its rectangular shape, and it was compared with the actual area (the actual area was divided by the area obtained with the assumption of a 3:2 rectangle). If the ratio was greater than 0.9 , then the value of the attribute was 2 . If it fell within the range of $0.5-0.9$ - the value of the attribute was 1 . If it was less than 0.5 , the attribute assumed the value of 0 .

The attribute of "area" assumed the value of 0 if a land plot area was greater than $1200 \mathrm{~m}^{2}$ (the greater the area, the lower the relative value of $1 \mathrm{~m}^{2}$ was). If the area was between $500-1200 \mathrm{~m}^{2}$, then the attribute assumed the value of 1 , whereas if the attribute was less than $500 \mathrm{~m}^{2}-2$. The abovespecified limits were determined on the grounds of an analysis of a shape ratio structure presented in Figure 1. It is quite distinctly noticeable that the number of real properties with a shape ratio of less than 0.5 was far lower than the number with that ratio being between 0.5-0.9. The greatest number of real properties was within the range of 0.9-1.1.

In Figure 2, sample distributions of individual attributes with which the analysed land real properties in Szczecin were described are shown.

Among the analysed land properties, the greatest number featured average or favourable physical 
properties. During the studied period, the data base included the greatest number of developed land plots, which seems completely accurate seeing as how the analysed area is located in a city. Real estate properties with complete utilities dominated in the data base. The analysed real estate featured only two variants of neighbourhood - average and favourable - with the average neighbourhood being predominant.

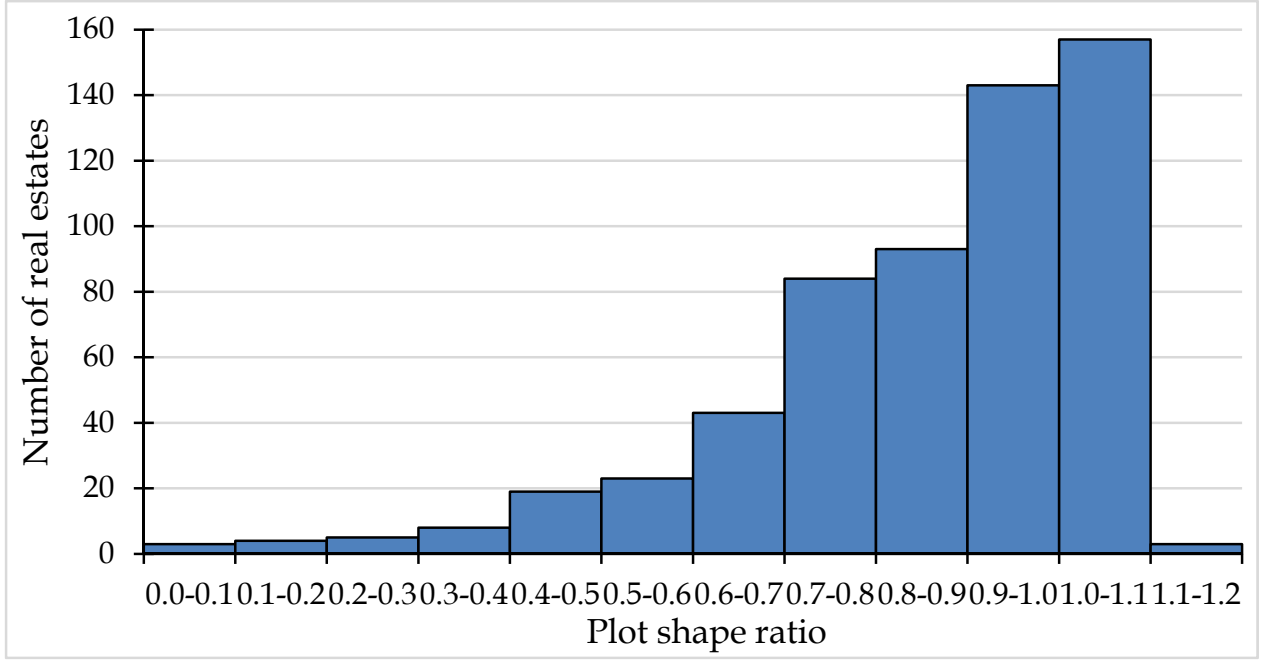

Fig. 1. The structure of the shape ratio. Source: own elaboration.

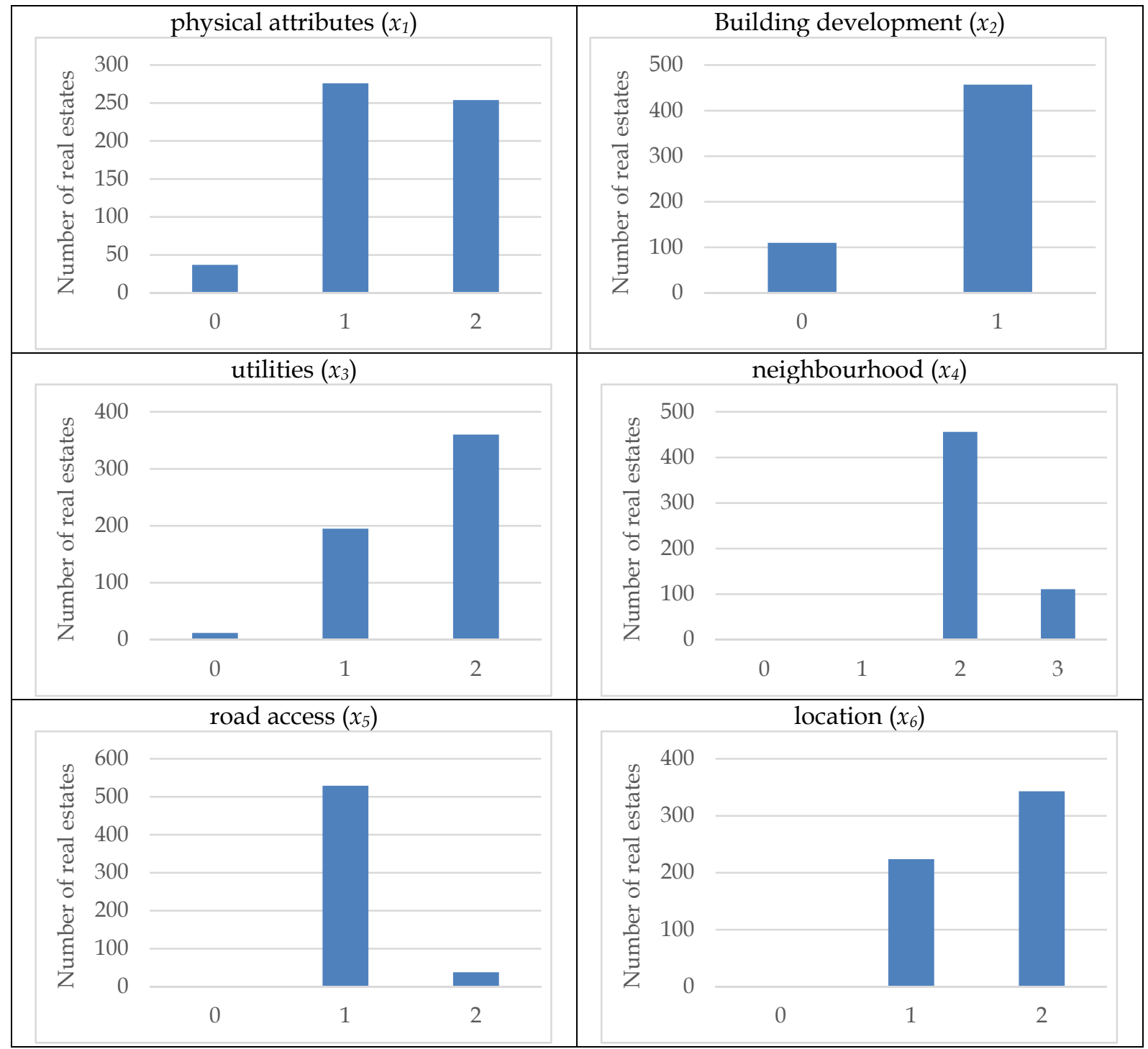




\section{S sciendo}

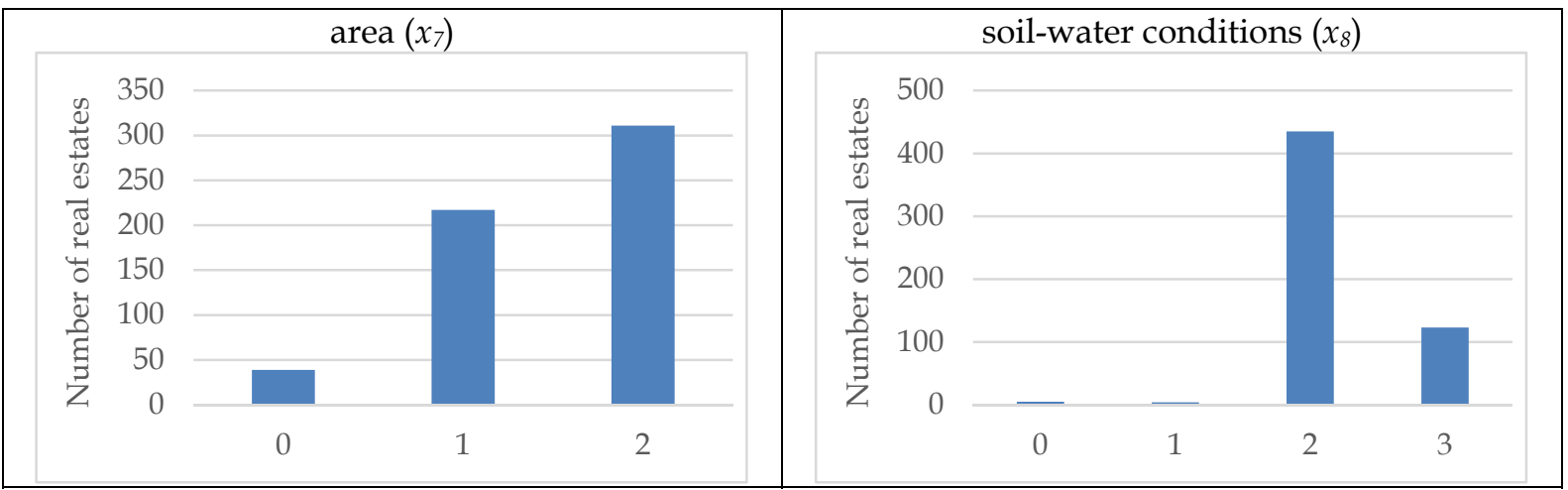

Fig. 2. Distributions of individual attribute variants. Source: own elaboration.

Over the analysed period, there were no real properties that would offer impeded access to a road. Real properties with average road access were dominant. During the studied period, the analysed land properties featured either an average or favourable location. The attribute of area was one of two attributes (the other being physical properties) for which all variants of the attributes occurred. The analysed real properties featured appropriate differentiation in terms of this attribute. In the analysed period, real properties with an area of up to $500 \mathrm{~m}^{2}$ were the most numerous.

\section{Empirical analysis of correlations and the impact of qualitative variables on real estate value}

Kendall's $\tau_{B}$ correlation coefficients, Spearman's $\rho$ coefficients as well as Kendall's $\tau_{y x, z}$, Spearman's $\rho_{y x}$ partial correlation coefficients and calculated on the basis of partial coefficients, corrected coefficients between the value of $1 \mathrm{~m}^{2}$ of a land property in Szczecin and individual characteristics (attributes) in 2005 have been presented in Table 1.

Table 1

Kendall's $\tau_{B}$ correlation coefficients, Spearman's $\rho$ coefficients partial correlation coefficients and corrected coefficients between the value of $1 \mathrm{~m}^{2}$ of a land property in Szczecin and individual characteristics (attributes) in 2005

\begin{tabular}{ccccccccc}
\hline Coefficients & $x_{1}$ & $x_{2}$ & $x_{3}$ & $x_{4}$ & $x_{5}$ & $x_{6}$ & $x_{7}$ & $x_{8}$ \\
\hline$\tau_{B}$ & 0.054 & $\mathbf{0 . 2 4 5}$ & $\mathbf{0 . 3 0 1}$ & $\mathbf{- 0 . 0 6 4}$ & $\mathbf{0 . 1 5 2}$ & $\mathbf{0 . 7 4 6}$ & $\mathbf{- 0 . 0 6 4}$ & $\mathbf{0 . 1 5 7}$ \\
\hline$\tau_{y x . z}$ & 0.029 & 0.024 & $\mathbf{0 . 5 0 8}$ & $\mathbf{0 . 1 4 3}$ & $\mathbf{0 . 1 9 8}$ & $\mathbf{0 . 8 0 1}$ & $\mathbf{0 . 1 4 2}$ & 0.020 \\
\hline Corrected $\tau_{y x . z}$ & - & - & $\mathbf{0 . 2 8 7}$ & $\mathbf{0 . 0 7 7}$ & $\mathbf{0 . 1 0 7}$ & $\mathbf{0 . 4 4 6}$ & $\mathbf{0 . 0 8 3}$ & - \\
\hline$\rho_{y x}$ & 0.063 & $\mathbf{0 . 2 7 7}$ & $\mathbf{0 . 3 4 3}$ & -0.058 & $\mathbf{0 . 1 7 5}$ & $\mathbf{0 . 8 5 9}$ & -0.068 & $\mathbf{0 . 1 9 3}$ \\
\hline$\rho_{y x . z}$ & $\mathbf{0 . 1 0 1}$ & 0.066 & $\mathbf{0 . 8 7 9}$ & $\mathbf{0 . 3 9 0}$ & $\mathbf{0 . 5 1 6}$ & $\mathbf{0 . 9 7 1}$ & $\mathbf{0 . 4 0 6}$ & $\mathbf{0 . 1 0 0}$ \\
\hline Corrected $\rho_{y x . z}$ & $\mathbf{0 . 0 3 0}$ & - & $\mathbf{0 . 2 6 1}$ & $\mathbf{0 . 1 1 6}$ & $\mathbf{0 . 1 5 3}$ & $\mathbf{0 . 2 8 9}$ & $\mathbf{0 . 1 2 1}$ & $\mathbf{0 . 0 3 0}$ \\
\hline
\end{tabular}

$x_{1}$ - physical properties, $x_{2}$ - building development, $x_{3}$ - utilities, $x_{4}-$ neighbourhood, $x_{5}-$ road access, $x_{6}-$ location, $x_{7}$ - area, $x_{8}$ - soil-water conditions. Coefficients significant at the significance level of 0.05 were bolded.

Source: own calculations.

When comparing Kendall's $\tau_{B}$ correlation coefficients and Kendall's $\tau_{y x . z}$ partial correlation coefficients it can be observed that their values differ quite substantially. This is particularly evident for the correlation between the value of $1 \mathrm{~m}^{2}$ and building development, neighbourhood, area and soil-water conditions. In the first case, an unrefined coefficient demonstrated the occurrence of a significant, though quite weak relationship between these two variables (the value of the coefficient amounted to 0.245 ), while a partial correlation coefficient (thus one refined from the influence of other attributes) demonstrated that there is virtually no correlation (the value of the coefficient amounted to 0.024). In the second and the third case, the situation was practically identical - unrefined coefficients showed the existence of a very weak, negative correlation between the value of one $\mathrm{m}^{2}$ and the analysed attributes (coefficient values amounted to approximately -0.06 , i.e. illogical conclusions may be drawn from it - the correlation value should not be negative). In turn, partial coefficients demonstrated the existence of a significant, though weak and positive correlation (with the values of partial coefficients at the level of 0.14 ). In the case of a relationship between the value of $1 \mathrm{~m}^{2}$ and soil- 
water conditions, the situation was similar to that of building development. An unrefined coefficient showed the existence of a weak, though significant correlation (the value of the coefficient was at the level of 0.157 ), while a partial correlation coefficient demonstrated a lack of any correlation between the examined properties (the value of the coefficient was equal to 0.02). Overall, apart from the location and utilities, the impact of the remaining attributes on the value of $1 \mathrm{~m}^{2}$ of land property was rather unsubstantial. Furthermore, unrefined coefficients at times indicated the existence of a negative correlation. That is why, it seems that when studying the relationship between the value of $1 \mathrm{~m}^{2}$ and individual attributes describing real properties, it is necessary to eliminate the influence of the remaining attributes (all partial correlation coefficients were positive). When comparing Spearman's $\rho_{y x}$ coefficient and Spearman's $\rho_{y x . z}$ partial correlation coefficient, a significant difference is further evident. In the case of physical properties, neighbourhood and area, the Spearman's $\rho_{y x}$ coefficients are insignificant, whereas in the calculation of Spearman's $\rho_{y x . z}$ partial correlation coefficient, they are significant in line with the observations made in practice. A reverse situation occurs in the event of an attribute describing real estate development.

It was examined whether individual attributes are mutually dependent. For that purpose, Kendall's $\tau_{y x . z}$ partial correlation coefficients (Table 2) and Spearman's $\rho_{y x . z}$ partial correlation coefficients (Table 3 ) were calculated between all the attributes.

Table 2

Matrix of Kendall's $\tau_{y x . z}$ partial correlation coefficients between attributes

\begin{tabular}{|c|c|c|c|c|c|c|c|}
\hline & $x_{2}$ & $x_{3}$ & $x_{4}$ & $x_{5}$ & $x_{6}$ & $x_{7}$ & $x_{8}$ \\
\hline$x_{1}$ & 0.146 & -0.098 & -0.069 & -0.129 & 0.012 & -0.287 & -0.068 \\
\hline$x_{2}$ & & 0.340 & 0.009 & -0.009 & 0.036 & 0.069 & 0.130 \\
\hline$x_{3}$ & & & -0.276 & -0.063 & -0.397 & -0.089 & $-0,335$ \\
\hline$x_{4}$ & & & & -0.104 & -0.168 & 0.006 & 0.178 \\
\hline$x_{5}$ & & & & & -0.111 & 0.076 & -0.116 \\
\hline$x_{6}$ & & & & & & -0.222 & 0.218 \\
\hline$x_{7}$ & & & & & & & -0.012 \\
\hline
\end{tabular}

$x_{1}$ - physical properties, $x_{2}$ - building development, $x_{3}$ - utilities, $x_{4}$ - neighbourhood, $x_{5}$ - road access, $x_{6}-$ location, $x_{7}$ - area, $x_{8}$ - soil-water conditions. Coefficients significant at a significance level of 0.05 were bolded. Source: own calculations.

As arises from Tables 2 and 3, the relationships between individual attributes were, in most cases, significant, but the correlation strength was at most medium. A strong correlation formed only between utilities and location (Table 3), and only for Spearman's $\rho_{y x . z}$ coefficient. Correlations computed on the grounds of Kendall's $\tau_{B}$ coefficient were, in most cases, weaker (in 22 out of 28 cases) than the corresponding Spearman's $\rho_{y x, z}$ partial correlation coefficients. An analysis of results presented in Tables 2 and 3 suggests that Kendall $\tau_{y x . z}$ partial correlation coefficients seem to be the better choice as a tool for determining the impact of attributes on the real estate unit value, because they generally indicate smaller interdependence between individual attributes.

Table 3

Matrix of Spearman's $\rho_{y x . z}$ partial correlation coefficients between attributes

\begin{tabular}{cccccccc}
\hline & $x_{2}$ & $x_{3}$ & $x_{4}$ & $x_{5}$ & $x_{6}$ & $x_{7}$ & $x_{8}$ \\
\hline$x_{1}$ & $\mathbf{0 . 1 3 1}$ & $\mathbf{- 0 . 1 3 4}$ & -0.087 & $-\mathbf{- 0 . 1 4 3}$ & -0.086 & $\mathbf{- 0 . 3 2 1}$ & -0.073 \\
\hline$x_{2}$ & & $\mathbf{0 . 1 3 3}$ & -0.019 & -0.029 & -0.044 & 0.021 & $\mathbf{0 . 1 1 1}$ \\
\hline$x_{3}$ & & -0.445 & -0.439 & -0.851 & -0.365 & -0.263 \\
\hline$x_{4}$ & & & -0.262 & -0.396 & -0.128 & $\mathbf{0 . 1 4 1}$ \\
\hline$x_{5}$ & & & & -0.482 & -0.112 & -0.158 \\
\hline$x_{6}$ & & & & & -0.434 & -0.003 \\
\hline$x_{7}$ & & & & & & -0.050 \\
\hline
\end{tabular}

$x_{1}-$ physical attributes, $x_{2}$ - building development, $x_{3}$ - utilities, $x_{4}$ - neighbourhood, $x_{5}$ - road access, $x_{6}-$ location, $x_{7}$ - area, $x_{8}$ - soil-water conditions. Coefficients significant at a significance level of 0.05 were bolded. Source: own calculations.

In Table 4, the results of an estimation of the impact exerted by individual states of attributes on real estate value are presented. 
Table 4

Calibration of the impact of individual attribute states on real estate value

\begin{tabular}{|c|c|c|c|c|c|c|c|}
\hline Attribute & $\begin{array}{c}\text { Attribute } \\
\text { variant }\end{array}$ & $\begin{array}{c}\text { Corrected } \\
\text { Spearman's } \\
\rho_{y x . z} \text { coefficient }\end{array}$ & $1+A_{k p i}$ & $A_{k p i}[\%]$ & $\begin{array}{c}\text { Corrected } \\
\text { Kendall's } \tau_{y x . z} \\
\text { coefficient }\end{array}$ & $1+A_{k p i}$ & $A_{k p i}[\%]$ \\
\hline \multirow{3}{*}{$\begin{array}{l}\text { Physical } \\
\text { properties }\end{array}$} & 0 & & 0.9849 & -1.51 & \multirow{3}{*}{-} & - & - \\
\hline & 1 & 0.030 & 1.0000 & 0 & & - & - \\
\hline & 2 & & 1.0151 & 1.51 & & - & - \\
\hline \multirow{3}{*}{ Utilities } & 0 & & 0.8694 & -13.06 & \multirow{3}{*}{0.287} & 0.8563 & -14.37 \\
\hline & 1 & 0.261 & 1.0000 & 0 & & 1.0000 & 0 \\
\hline & 2 & & 1.1306 & 13.06 & & 1.1437 & 14.37 \\
\hline \multirow{2}{*}{ Neighbourhood } & 2 & \multirow{2}{*}{0.116} & 0.9420 & -5.8 & \multirow{2}{*}{0.077} & 0.9614 & -3.86 \\
\hline & 3 & & 1.0580 & 5.8 & & 1.0386 & 3.86 \\
\hline \multirow{3}{*}{ Road access } & 0 & & 0.9233 & -7.67 & \multirow{3}{*}{0.107} & 0.9466 & -5.34 \\
\hline & 1 & 0.153 & 1.0000 & 0 & & 1.0000 & 0 \\
\hline & 2 & & 1.0767 & 7.67 & & 1.0534 & 5.34 \\
\hline \multirow{2}{*}{ Location } & 1 & \multirow{2}{*}{0.289} & 0.8556 & -14.44 & \multirow{2}{*}{0.446} & 0.7771 & -22.29 \\
\hline & 2 & & 1.1444 & 14.44 & & 1.2229 & 22.29 \\
\hline \multirow{3}{*}{ Area } & 0 & & 0.9396 & -6.04 & \multirow{3}{*}{0.083} & 0.9586 & -4.14 \\
\hline & 1 & 0.121 & 1.0000 & 0 & & 1.0000 & 0 \\
\hline & 2 & & 1.0604 & 6.04 & & 1.0414 & 4.14 \\
\hline \multirow{4}{*}{$\begin{array}{l}\text { Soil-water } \\
\text { conditions }\end{array}$} & 0 & \multirow{4}{*}{0.030} & 0.9852 & -1.48 & \multirow{4}{*}{ - } & - & - \\
\hline & 1 & & 0.9951 & -0.49 & & - & - \\
\hline & 2 & & 1.0049 & 0.49 & & - & - \\
\hline & 3 & & 1.0148 & 1.48 & & - & - \\
\hline
\end{tabular}

Source: own calculations.

For a corrected Spearman's $\rho_{y x . z}$ coefficient, location and utilities had the greatest influence on a real estate value, whereas soil-water conditions affected it the least. In case of utilities, for example, a real estate value without utilities was $13.06 \%$ lower than the value of a plot fitted out with only partial utilities. In the case of a corrected Kendall's $\tau_{y x . z}$ coefficient, utilities and location exerted the greatest impact on a real estate value. The attributes of physical properties as well as soil-water conditions appeared to be insignificant (for the method using the corrected Kendall's $\tau_{y x . z}$ coefficient). In the case of attributes such as: utilities and location, their impact on real estate value was greater when a corrected Kendall's $\tau_{y x . z}$ coefficient was employed than was the case for a corrected Spearman's $\rho_{y x, z}$ coefficient. In turn, the attributes of: neighbourhood, road access, area, their impact on a real estate value was lower than with the application of a corrected Spearman's $\rho_{y x . z}$ coefficient.

Table 5 contains the values of market value ratios (WWRj) evaluated for individual location attractiveness zones with the use of SAREMA. The subsequent columns present the results of compliance measurements of real estate values for 56 real properties randomly selected and appraised with SAREMA as well as by property appraisers. The calculations were carried out in two variants, i.e.: with the use of corrected Spearman's $\rho_{y x . z}$ and Kendall's $\tau_{y x . z}$ coefficients.

From the conducted analyses it unequivocally arises that, in both variants, higher prices were noted in the following location attractiveness zones: 5, 6 and 7. The application of a corrected $\tau_{B}$ Kendall coefficient (II method) in location attractiveness zones 3, 6 and 7yields a far better fit of theoretical land values with market values than the application of corrected Spearman's $\rho_{y x . z}$ coefficient. For location attractiveness zones 4 and 5 slightly better valuations were obtained for the corrected Spearman's $\rho_{y x . z}$ coefficient.

When applying a corrected Spearman's $\rho_{y x, z}$ coefficient to the valuation of $1 \mathrm{~m}^{2}$ of real estate, its value in the cheapest location attractiveness zone $\left(4^{\text {th }}\right)$ was, on average, $15.8 \%$ lower than the 
hypothetical value of $1 \mathrm{~m}^{2}$ of real estate with the medium variants of all attributes $\left(W W R_{j}=0.842\right)$. On the contrary, in the most expensive, $6^{\text {th }}$ location attractiveness zone, the unit value of real estate was, on average, $22.8 \%$ higher. Application of the corrected Kendall's $\tau_{y x . z}$ coefficient resulted in the unit real estate value in the cheapest $4^{\text {th }}$ location attractiveness being lower, on average, by $18.2 \%$ than the hypothetical value of $1 \mathrm{~m}^{2}$ of real estate with the medium variants of all attributes and in the most expensive, i.e. $6^{\text {th }}$ location - on average $8.7 \%$ higher.

Table 5

Market value coefficients for individual location attractiveness zones and the compliance of the results and property appraiser's valuations (for 56 real properties)

\begin{tabular}{ccccc}
\hline Location & Corrected Spearman's $\rho_{y x . z}$ coefficient & Corrected Kendall's $\tau_{y x . z}$ coefficient \\
\cline { 2 - 5 } attractiveness zone & $W W R_{j}$ & $M A P E$ & $W W R_{j}$ & MAPE \\
\hline 3 & 0.902 & 8.300 & 0.858 & 6.376 \\
\hline 4 & 0.842 & 1.621 & 0.818 & 1.823 \\
\hline 5 & 1.133 & 4.244 & 1.000 & 3.232 \\
\hline 6 & 1.228 & 5.104 & 1.087 & 3.702 \\
\hline 7 & 1.110 & 3.013 & 0.974 & 2.610 \\
\hline
\end{tabular}

Source: own calculations.

The largest valuation errors were obtained for the $3^{\text {rd }}$ location attractiveness zone. When employing a corrected Spearman's $\rho_{y x . z}$ coefficient to the valuation of $1 \mathrm{~m}^{2}$ of real estate, the value of a real property valued by the algorithm typically differed from the value of $1 \mathrm{~m}^{2}$ of land valued by a property appraiser by $+/-8.3 \%$, whereas when corrected Kendall's $\tau_{y x . z}$ coefficient was employed for the same location attractiveness zone, this error was equal $+/-6.376 \%$. The smallest errors were obtained for the $4^{\text {th }}$ location attractiveness zone - application of the corrected Spearman's $\rho_{y x . z}$ coefficient set it at the level of $+/-1.621 \%$, whereas when the corrected Kendall's $\tau_{y x . z}$ coefficient was applied, its value was equal $+/-1.823 \%$.

All of the obtained results show that application of both corrected Spearman's $\rho_{y x . z}$ coefficients or corrected Kendall's $\tau_{y x . z}$ coefficients for the calibration of the impact of individual attribute states on real estate value yields good results. However, the application of the latter gave, in most cases, better results than the former one. Further confirmation of the superiority of the corrected Kendall's $\tau_{y x . z}$ coefficient lies in the analysis of mutual relationships between the attributes (Tables 2 and 3) - this coefficient indicates a weaker correlation between attributes. Moreover, for the scale which the attributes are measured on, it is more appropriate to determine only the surpassing relationship, not the differences between the ranks.

\section{Conclusion}

The use of coefficients for the analysis of correlations between real estate attributes is determined by the fact of what measurement scale can be used for their presentation. Qualitative properties presented on a nominal or ordinal scale require the use of suitable coefficients, e.g. the proposed: Kendall's $\tau$, Spearman's $\rho$, or measurements based on $\chi^{2}$ statistics.

The analysis of statistical data demonstrated that the examined real estate frequently failed to show differentiation on account of the analysed attributes - the real properties were similar to one another. However, such variability is required if statistical methods are employed. Its lack means that certain correlations cannot be subjected to statistical calculations.

On the grounds of the coefficients calculated, it can be observed that the greatest impact on the value of $1 \mathrm{~m}^{2}$ of land real estate in Szczecin was exerted by its location, followed by utilities and road access. Physical properties and the status of a plot development had virtually no influence on the value of $1 \mathrm{~m}^{2}$. The impact of the remaining variables was significant, although in the case of the variable of neighbourhood and area, the values of coefficients were practically equal to 0 , i.e. these properties also did not influence the value of the explained variable. In summary - apart from the location, the impact of the remaining qualities on the value of $1 \mathrm{~m}^{2}$ of land real estate was rather insignificant.

In many cases, there were substantial differences between the values of unrefined correlation coefficients from the influence of the remaining attributes and partial correlation coefficients. That is why, when analysing the impact of individual attributes on the value of $1 \mathrm{~m}^{2}$ of real estate, coefficients 


\section{S sciendo}

refined from that influence (partial coefficients) ought to be taken into consideration.

The analysis of relationships between real estate attributes showed that, generally speaking, correlation coefficients between them were significant, but at most of medium strength (with the exception of the Spearman's $\rho_{y x . z}$ partial correlation coefficient between the utilities and location, where the correlation was strong). Also, in most cases, the Kendall's $\tau_{y x . z}$ coefficients indicated on weaker relationship between the attributes than the Spearman's $\rho_{y x . z}$ coefficient. Lack of strong correlations between attributes demonstrates that the attributes are not collinear - they do not "convey" similar information.

The conducted study demonstrates that the proposed correlation coefficients - Kendall's $\tau_{B}$ and Spearman's $\rho$ coefficients - can be used as the basis for estimating weights of the impact of individual attributes on real estate value. They are methodologically correct (the attributes were presented on ordinal scales). Generally, better results of valuation compliance with individual appraisals were obtained in the case of Kendall's $\tau_{B}$ coefficient. This also seems to be more methodologically correct with respect to the mathematical operations permitted on such a scale (determining rather the relationships of surpassing, than differences between the ranks). Therefore, it is recommended that Kendall $\tau_{y x . z}$ partial correlation coefficient be used as a measure of correlation between the real estate price of $1 \mathrm{~m}^{2}$ and the values of attributes.

\section{Bibliography}

Barańska, A. (2009). Qualitative and quantitative methods for assessing the similarity of real estate. Value in the Process of Real Estate Management and Land Administration, Towarzystwo Naukowe Nieruchomości, Olsztyn,31-42.

Babatunde, I.O., (2018). Examining Heuristics for Building - Work-In-Progress Valuations in Niger State Nigeria. Real Estate Management and Valuation, 26(2), 92-103. https://doi.org/10.2478/remav2018-0019.

Bell, R. \& Bell, M.P. (2015). Real Estate Research Methods. The Appraisal Journal, 310-318.

Butryn, K. \& Preweda, E. (2017). Analysis of the impact of quantitative and qualitative price-setting attributes on a market of real estate intended for the purpose of the transformer stations on the example of Krakow. 10th International Conference on Environmental Engineering, ICEE, https://doi.org/10.3846/enviro.2017.177.

Doszyń, M. (2017). Statistical Determination of Impact of Property Attributes for Weak Measurement Scales. Real Estate Management and Valuation, 25(4), 75-84. https://doi.org/10.1515/remav-20170031.

Gaca, R. (2018). Parametric and Non-Parametric Statistical Methods in the Assessment of the Effect of Property Attributes on Prices. Real Estate Management and Valuation, 26(2), 83-91. https://doi.org/10.2478/remav-2018-0018.

Foryś, I. \& Gaca, R. (2016). Application of the Likert and Osgood Scales to Quantify the Qualitative Features of Real Estate Properties. Folia Oeconomica Stetinensia, 16(2), 7-16.

Kendall, M.G. (1948). Rank Correlation Methods. Charles Griffin \& Company Limited, London.

Kendall, M.G. (1955). Rank Correlation Methods. Hafner Publishing Co., New York.

Kolenda, M. (2006). Taksonomia numeryczna. Klasyfikacja, porządkowanie i analiza obiektów wielocechowych (Numerical Taxonomy: Classification, Ranking and Analysis of Multivariable Objects). Wydawnictwo Akademii Ekonomicznej im. Oskara Langego we Wrocławiu, Wrocław.

Kulczycki, M. \& Ligas M. (2014). Qualitative Similarity Coefficients in Real Estate Market Analysis. Geomatics and Environental Engineering, 8(1), 33-41.

Lis, Ch. (2008). Wykorzystanie metod ilościowych w procesie powszechnej taksacji nieruchomości w Polsce (The Application of Quantitative Methods in the Process of Common Property Taxation in Poland). Prace Naukowe Akademia Ekonomiczna w Katowicach, Modelowanie matematyczne $i$ ekonometryczne na polskim rynku finansowym, 191-204.

Steczkowski, J. \& Zeliaś, A. (1997). Metody statystyczne w badaniu zjawisk jakościowych (Statistical Methods in the Study of Qualitative Phenomena). Akademia Ekonomiczna w Krakowie, Kraków.

Stevens, S.S. (1946). On the Theory of Scales of Measurement. Science, 103 (67), 677-680.

Walesiak, M. (1996). Dopuszczalne działania na liczbach w badaniach marketingowych z punku widzenia skal pomiarowych (Acceptable Actions on Numbers in Marketing Research From the Point of View of Measurement Scales). Prace Naukowe Akademii Ekonomicznej we Wroctawiu, $n r$ 718, Informatyka i Ekonometria 1, 103-110. 